\title{
Scanning Electron Microscope Studies on Rabbit Renal Glomerulus, with Special Reference to "Podocytic Membrane" of ELIAS and to Pored Domes on Capillary Endothelium
}

\author{
Toshimi Yoshinari and Tsuneo FujITA
}

Departments of Pediatrics (Prof. K. SAKAI) and Anatomy (Prof. T. FujITA), Niigata University School of Medicine, Niigata, Japan

Received September 1, 1981

Summary. In their transmission electron microscope (TEM) study of the rabbit kidney, ELIAS et al. (1964, 1966) reported an occurrence of "podocytic membranes" which were attenuated parts of the body of the podocytes covering the processes and pedicels of podocytes and forming closed spaces, "subpodocytic lacunae" (Fig. 1, 2).

In this scanning electron microscope (SEM) study, we demonstrate the three-dimensional structure of rabbit podocytes which largely confirms the ELIAS' diagram. However, the "podocytic membranes" are not as in ELIAS' view, attenuated portions of the body of the podocytes, but correspond to their primary processes which are flattened into plates in this species. The "podocytic membranes" do not represent a second filtration barrier for the primary urine, which Elias proposed.

On the glomerular endothelium, we found domed microprojections consisting of a pored cytoplasmic sheet not only in the attenuated portions of the endothelium or areolae fenestratae, but also in the nuclear portion of the endothelial cells. This hitherto unknown distribution of pored cytoplasm necessitates revision of the previous view which has interpreted the significance of the endothelial pores only from the aspect of substance transport through the capillary wall.

In their transmission electron microscope (TEM) study of the rabbit glomerulus, ELIAS and his associates (1964) found that parts of the body of the podocyte extended into attenuated plates called "podocytic membranes" which covered many podocyte processes and their pedicels (Fig. 1, 2). Generalizing this finding in the rabbit to other species, they proposed that these podocytic membranes must be an important structure which formed closed spaces, "subpodocytic lacunae" over the glomerular basement membrane and pooled the primary urine which had filtrated through it. The podocytic membranes were thus visualised as a second barrier in urine filtration.

Although numerous scanning electron microscope (SEM) studies elucidated the real shapes of mammalian podocytes, the occurrence of the podocytic membranes has not previously been confirmed, except for a brief mention by ARAKAwA (1974) on their occurrence in the rabbit glomerulus. The present SEM observation aims to examine the 
occurrence and nature of the podocytic membranes by using the rabbit which was the starting material of EliAs' argument.

During this study, we noticed that the pores of the endothelium lining the glomerular capillaries were not so simple in structure and location as had been described in previous TEM studies. Pored endothelial structures are not only two-dimensional extentions forming the areolae fenestratae of the capillary wall, but also are threedimensional constructions forming domed and caveolar bodies on the areolae fenestratae and also on thicker portions of the endothelium. This fact has been pointed out, though insufficiently, by WOLFF (1966) and WOLFF and MERKER (1966) in their TEM study of the rat kidney and by FuJITA et al. (1976) in their SEM observation on the rat kidney, but has generally been overlooked either intentionally or unintentionally by electron microscopists. The present paper therefore includes observations and discussion on the peculiar caveolar and domed-pored structures on the glomerular endothelial surface in the rabbit.

\section{MATERIALS AND METHODS}

Female rabbits weighing $2.5-3.5 \mathrm{~kg}$ were used. The animals were anesthetized with nembutal injected intravenously. The kidney was perfused from the abdominal aorta with warmed Ringer solution and then with $2.5 \%$ glutaraldehyde $(0.1 \mathrm{M}$ phosphate buffer, $\mathrm{pH}$ 7.4). After several hours the cortex of the kidney was cut into small pieces which were kept in the same fixative for a few days and treated with the tanninosmium impregnation method of MURAKAMI (1974).

After dehydration in an ascending ethanol series, the tissue pieces were immersed in isoamyl acetate, frozen in Freon-22 cooled by liquid nitrogen, and fractured with a chisel and hammer (TokunAga et al., 1974). The cracked specimens were immersed in isoamyl acetate again and then dried by the $\mathrm{CO}_{2}$ critical point method. The dried specimens were pasted on metal stubs, evaporated with gold-palladium, and observed in a field emission type SEM (HFS-2, Hitachi Manufacturing Co.).

\section{RESULTS}

\section{Podocytes}

Low-power view of the rabbit glomerulus demonstrated the cell bodies of podocytes lying on the loops of blood capillaries, winding like intestines (Fig. 3). Many of the cell bodies of the podocytes lay inside of the curves of the capillary convolution, but some others were attached to the convex wall of the capillaries. The cells tended to be distributed at rather irregular distances, and occasionally several cell bodies were seen closely gathered together (Fig. 4).

The surface of the cell bodies of the podocytes was smooth and round, and some microvilli were seen on it. Most of the microvilli were short but some were long and protruded into the urinary space. Microvilli were seen also on the podocyte processes and foot processes (pedicels).

Some five to seven processes were issued from the peripheral margin of the cell body. The sizes of these primary processes were very variable. Most of them were long and wide, distributing secondary and tertiary processes and pedicels (vide infra) to a distance (Fig. 3). 


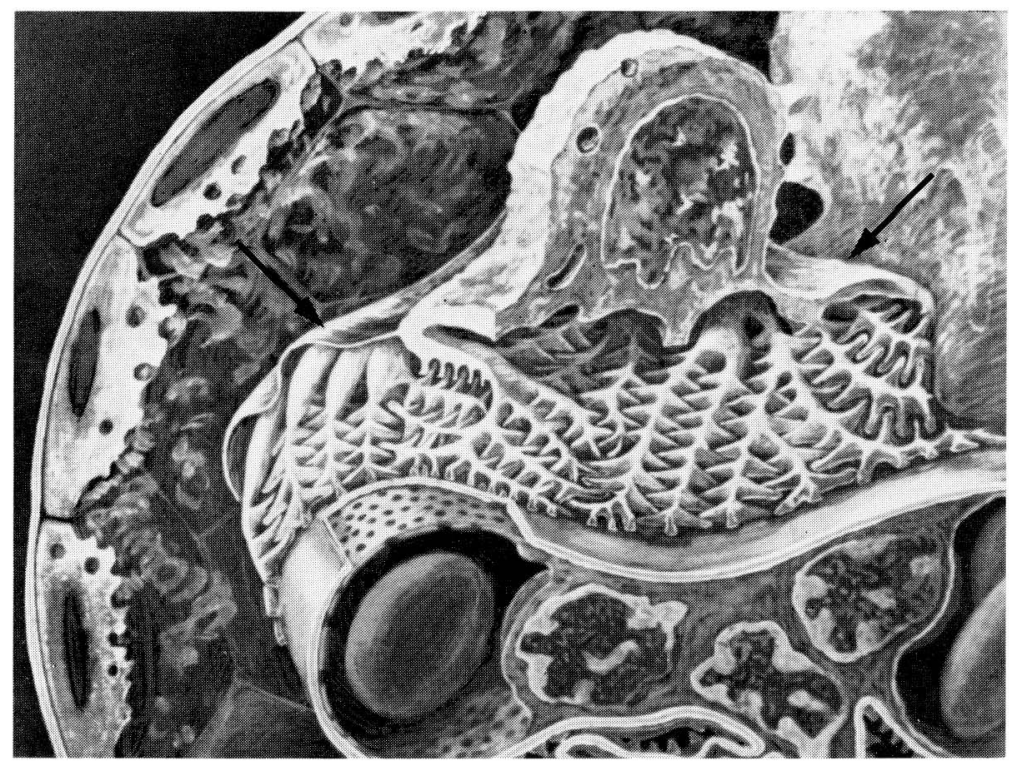

Fig. 1. Diagram showing the three-dimensional visualization by ELIAs and associates concerning the podocyte and "podocytic membrane (arrows)." The picture is reproduced under permission from Histology and Human Microanatomy by Elias, Pauly and Burns, 4th ed., Piccin Medical Book, Padova, 1978, p. 410. (The arrows were added by the present authors).

Noteworthily, most of the primary processes were flattened into plates, which have not been reported in other species. The plate-like primary processes were occasionally so well developed that they exceeded $25 \mu \mathrm{m}$ in length and $7 \mu \mathrm{m}$ in width. They lifted themselves over the surface of the capillary loops, and covered the processes of podocytes. Some of them appeared just like conspicuous "roofs" (Fig. 5).

Most, if not all, of the primary processes issued some secondary processes from their lateral sides. Occasionally tertiary processes were ramified from the secondary processes. The foot processes or pedicels were generally issued from the sides of the secondary or tertiary processes. Some pedicels emerged from the primary processes (Fig. 8). Only a few were issued from the cell body directly. Anastomosis or bridge formation between two adjacent processes was often observed in the primary, secondary and tertiary process levels (Fig. 6).

The pedicels of the rabbit podocyte were generally thin columnar processes, thickening irregularly at places. They often ramified dichotomically. Some pedicels were flattened and wide, forming into a leaf-like shape (Fig. 7, 8).

\section{Endothelium}

The endothelial surface structure was observed in the glomerular capillaries opened by freeze fracture. The nuclear portion of endothelial cell bulged into the lumen. The flat and pored areas, areolae fenestratae of the endothelium, were separated by branching and anastomosing cytoplasmic crests radiated from the nuclear portion to the periphery of the endothelial cell. The cell margin was represented by a crest which ran closely parallel to the marginal crest of the adjacent endothelial cell. The intercellular boundary was thus marked as a slit between a pair of parallel crests (Fig. 10). 


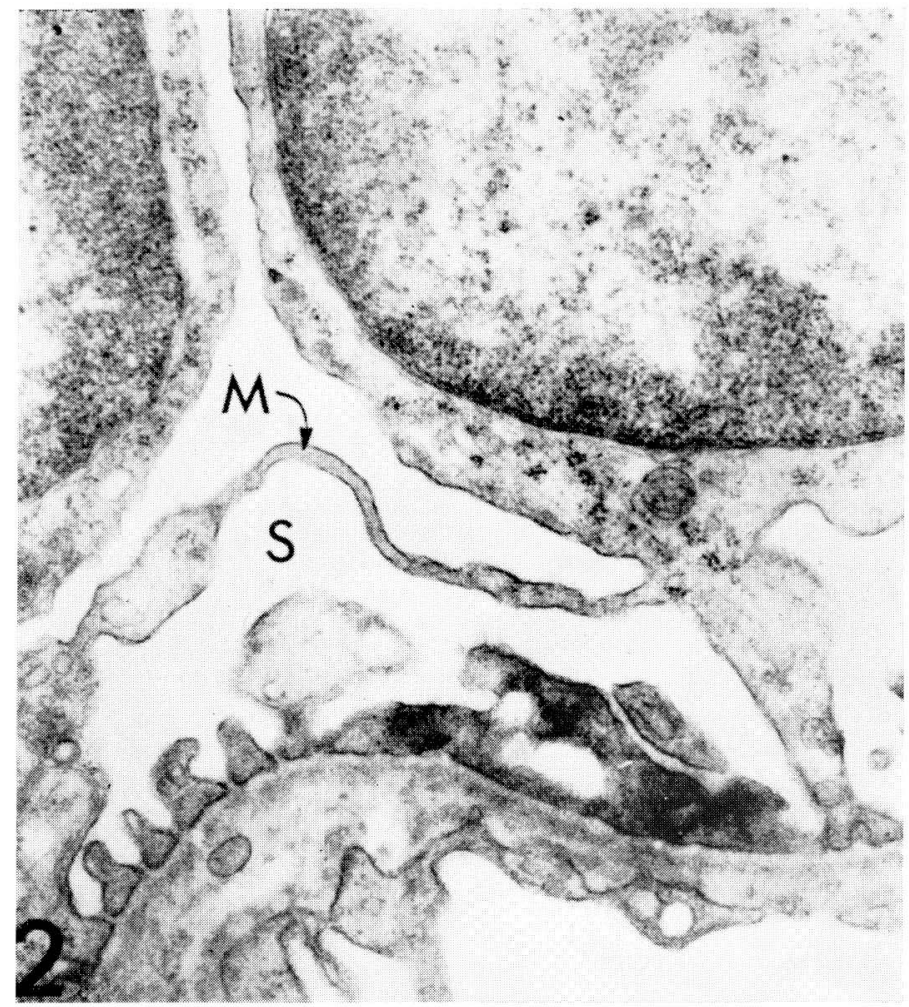

Fig. 2. TEM image of rabbit podocyte showing a "podocytic membrane" $(M)$ covering a space "subpodocytic lacuna" $(S)$, reproduced under permission from the same book by ELIAS, PAULY and BURNS.

The areolae fenestratae were perforated with pores which were round, oval or irregular in shape and, as previously pointed out in the SEM observation in the rat glomerulus (Fujita et al., 1976), conspicuously variable in size, ranging from 15 to $150 \mathrm{~nm}$ in diameter.

The areolae fenestratae were generally flat, but a few villous and polypous microprojections were demonstrated (Fig. 9). More noteworthily, some polypous and domelike elevations were formed by a cytoplasmic sheet with the same perforations as those in the areola fenestrata. Some endothelial cells had many microprojections and pored domes, but others had only a few (Fig. 10).

The nuclear swelling and cytoplasmic crests were generally smooth in surface but microprojections and pored domes as well as some pits were often seen on them (Fig. 11). Every gradation between a simple and small elevation of the pored endothelium and the large pored domes could be demonstrated. Some of them developed into towerlike structures with numerous pores on them and protruded into the capillary lumen.

Fig. 3. Low power view of rabbit glomerular podocytes. Most of the primary processes are long and wide, issuing secondary and tertiary processes and pedicels. Note that in the rabbit, some of the primary prcoesses are conspicuously flattened into plates (arrows). The podocyte at the upper middle is showed in Figure 5 in higher magnification. $\times 4,300$

Fig. 4. Several cell bodies of podocytes are seen closely gathered. This uneven distribution of podocytes is also characteristic of the rabbit. $\times 6,000$ 


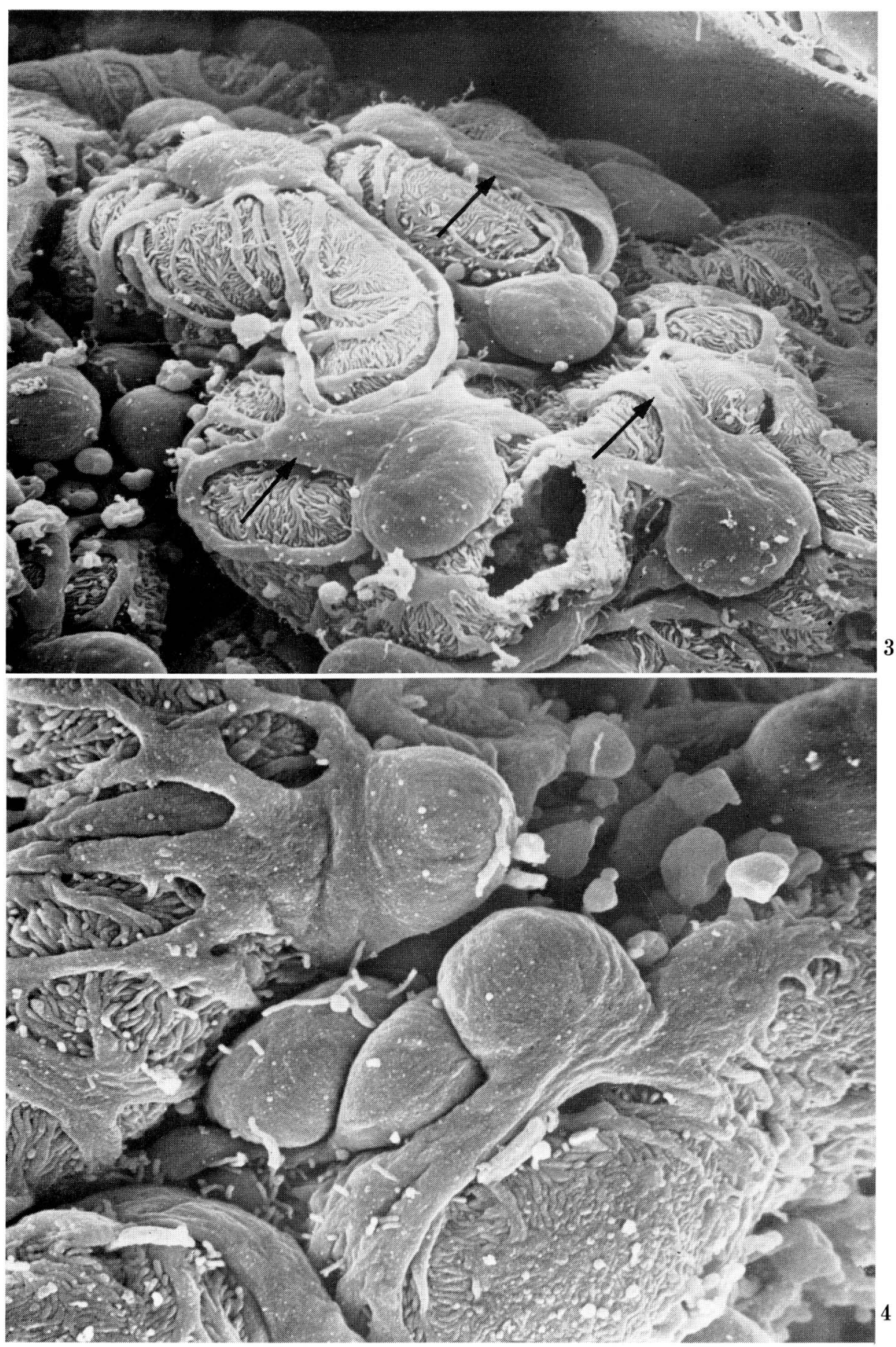

Fig. 3 and 4. Legends on the opposite page. 


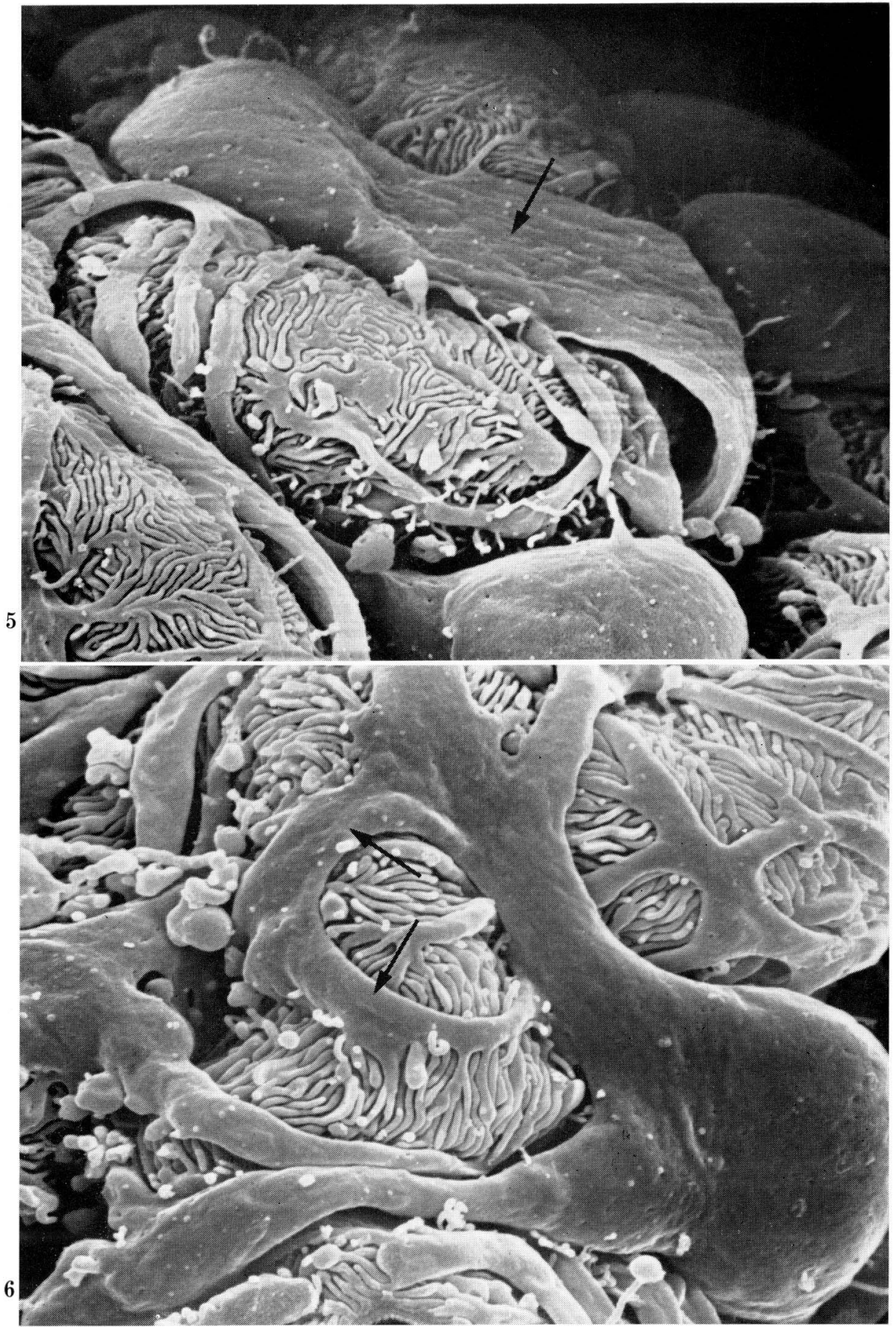

Fig. 5. A podocyte with a conspicuous "roof" (arrow) of the primary process. A view which precisely coincides with what was proposed in EliAs' diagram (Fig. 1). $\times 10,700$

Fig. 6. A podocyte whose processes are flattened and wide. Note that the secondary processes (arrows) are anastomosed between themselves, forming a loop. $\times 13,000$ 

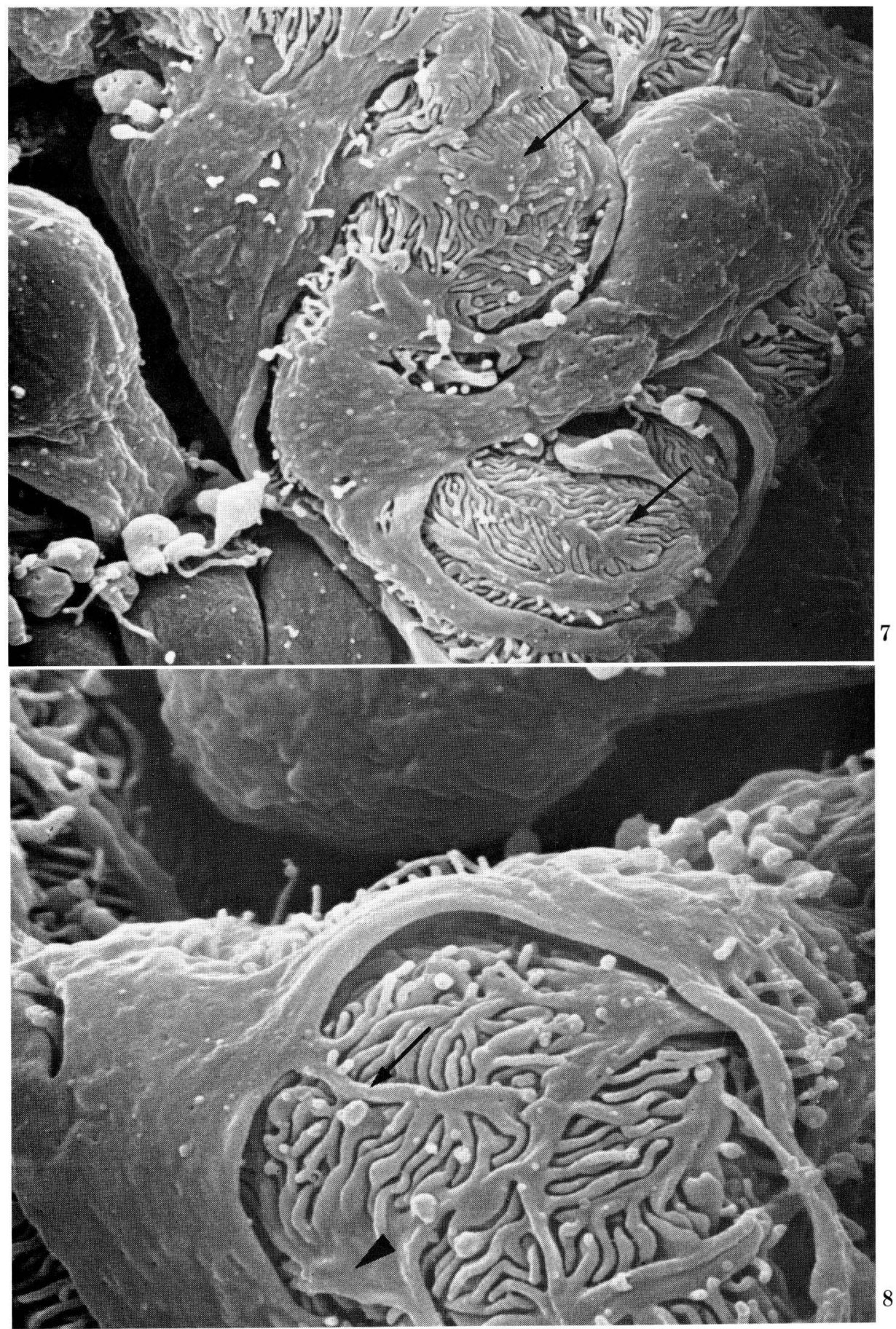

Fig. 7. Primary processes of podocytes, which are flattened into plates, issue secondary processes and pedicels directly. Some of the podocyte pedicels are flattened and wide, forming leaf-like plates (arrows). $\quad \times 8,600$

Fig 8. A podocyte pedicel, which issues directly from a primary process (arrow). Some pedicels are flattened and wide forming leaf-like plates (arrow head). $\quad \times 19,000$ 


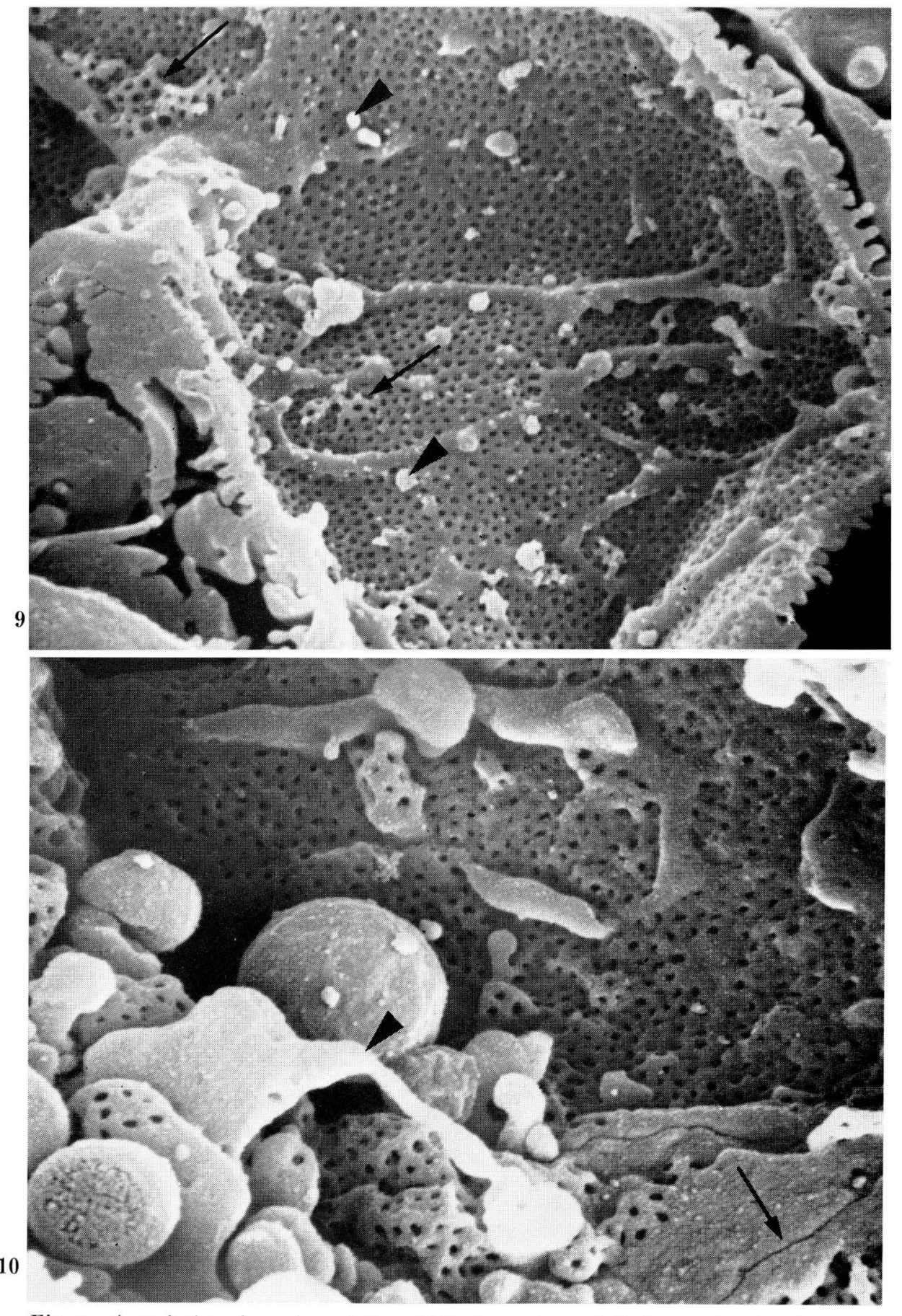

Fig. 9. A typical surface view of the rabbit glomerular endothelium. Cytoplasmic crests border fenestrated areas (areolae fenestratae). Microvilli (arrow heads), and pored domes (arrows) are seen only occasionaly. $\times 22,000$

Fig. 10. Legend on the opposite page. 


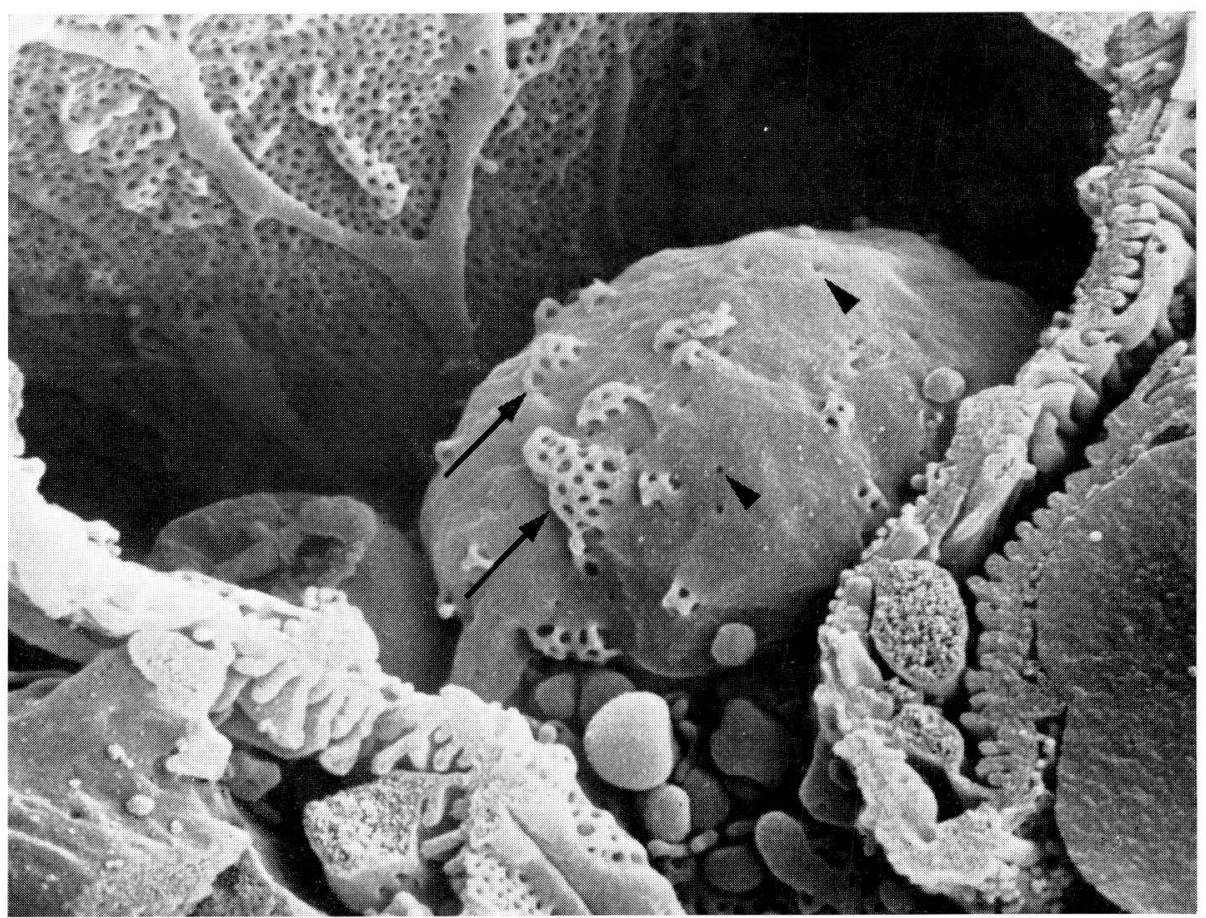

Fig. 11. A portion of a glomelular capillary. The nuclear portion of an endothelial cell bulges into the lumen. Microprojections mostly forming pored domes (arrows) and some pits (arrow heads) are seen on its surfaces. $\quad \times 24,000$

The pored domes on the nuclear portion seemed to be completely identical in structure with the pored domes on the areolae fenestratae.

\section{DISCUSSION}

\section{Podocytes}

The present observation confirms the description by FuJiTA et al. (1970) that in the rabbit the pattern of ramification of the podocyte processes is irregular when compared with other species like the human and rat. The irregularity was noticed in the size and branching mode of the primary and secondary processes, as well as in the distribution and interdigitation pattern of the end feet. The frequent anastomosis or bridge formation between two adjacent processes of primary, secondary and tertiary levels is also characteristic of the rabbit.

In their TEM study of rabbit glomerular podocytes, ELIAs et al. (1964) reported a peculiar structure which they named the "podocytic membrane" (Fig. 2). They thought that the podocytic membrane, a plate-like attenuation of the podocyte cell body, formed

Fig. 10. A part of the glomerular endothelium rich in perforated projections (pored domes). The pored domes vary greatly in size, and thier surfaces are irregular. One of the pored domes which has a few pores on it protrudes into the capillary lumen, and one long process of the pored dome extends from it like a bridge (arrow head). Some microvilli and possible plasma protein residues are seen. The slit (arrow) between the parallel crests of the endothelium is the boundary of adjacent endothelial cells. $\times 32,000$ 
a closed space-"subpodocytic lacuna"-over the glomerular basement membrane, pooled the primary urine and acted as a second barrier in urine filtration. On the basis of this finding in a specific species, Elias and PaUly (1966; see also Elias, Pauly and BuRns, 1978) published a three-dimensional diagram showing the podocytic membrane hanging over the glomerular filtration barrier(Fig. 1).

In this SEM study, we obtained a three-dimensional visualization of the podocytic membrane which, in fractured appearances, coincided with the diagram from ELIAS and PAULY which was based on their TEM observation of thin sections (Fig. 1). We found, however, that podocytic membranes were not the attenuated extentions from the body of the podocytes as Elias and associates reported, but corresponded to the primary processes which were flattened into plates. Furthermore, our SEM observation indicates that the "podocytic membrane" does not cover a closed "lacuna" for "pooling the primary urine "which Elias and associates postulated as occurring. The possible roles of the podocytic membrane found by ELIAS, an explorer of three-dimensional microanatomy, deserves future investigation, but its significance as a second barrier in glomerular filtration is denied in the present study.

Elias et al. (1978) described and illustrated the occurrence of some desmosomes between two neighboring cell bodies of podocytes (Fig. 1). We found that podocyte cell bodies were sometimes closely gathered in the rabbit, but the occurrence of desmosomes among them is not a subject to be defined by SEM.

\section{Endothelium}

The pored domes on the attenuated and pored portions or areolae fenestratae of capillary endothelium were roported by WoLfF (1966) and WolfF and MERKER (1966) in their TEM studies. They thought that the endothelial pores were formed by pinocytosis-like invaginations and vesiculations, and they presumed that the pored domes were caused by the formation of larger vacuoles in the endothelium and by pores which atypically opened into the vacuoles.

FujITA et al. (1976) demonstrated the pored domes in their SEM study of rat glomerular endothelium, but their interpretations differed from those of WoLfF and Merker (1966). They suggested that the pored domes might be formed by anastomosis of microvilli and might be involved in the replacement of worn-out parts of the endothelium.

In his TEM study of capillary endothelium, KoBAy Ashi (1970a, b) proposed that the substance transport across the capillary wall might not be by a pinocytotic membrane movement ("transport in quanta" proposed by PALADE, 1953, 1960), but rather a flow of substances through the fenestrae and channels tunneling across the endothelium ("transport in continuum"). It may be possible that some of the pored structures demonstrated by SEM correspond to the orifices of the tunnels through the endothelium.

In this study, however, we found that typical pored domes occur even on the cell body or nuclear swelling of an endothelial cell. It is unlikely that the openings of "channels" might occur at this site of cell thickening. Moreover, the domes on the nuclear swelling, as in areolae fenestratae, appear to consist of a pored plate covering a cavity, not continuing to form deeper tunneling structures. Pored plates on the nuclear swelling identical with, but less conspicuous than, those demonstrated in this study have been reported in a previous SEM study in the rat (FuJiTA et al., 1976).

It is thus suggested that the superficial cytoplasm of glomerular endothelium might possess an intrinsic ability or tendency to form a pored plate, and that this might be manifested as the formation of domes not only on the areolae fenestratae but also on the 
nuclear swelling of the endothelium. The causes which might induce the formation of the pored domes and their functions, if any, remain unknown.

Acknowledgements. We are deeply grateful to Professor Hans Elias of the University of California School of Medicine for his kindly granting us permission for the reproduction of his pictures and for his precious advice. Thanks are also due to the technical help of Mr. K. AdAchi, SEM Laboratory, Niigata University Medical School.

\section{REFERENCES}

Arakawa, M., J. Tokunaga, T. Shimotori and Y. Kinoshita: A scanning electron microscope study of the glomerulus of normal and nephritic rabbits. Virchows Arch. B Cell Pathol. 17: 185-194 (1974).

Elias, H., E. Allara, P. M. Elias and A. S. Krishna Murthy : The podocytes, re-examined. Z. mikrosk.-anat. Forsch. 72: 344-365 (1964).

Elias H. and J. E. Pauly: Human microanatomy. 3rd ed., F. A. Davis Co., Philadelphia, 1966 (p. 241259).

Elias H., J. E. Pauly and E. R. Burns : Histology and human microanatomy. 4th ed. Piccin Medical Books, Padova, 1978 (p. 389-421).

Fujita, T., J. Tokunaga and M. Edanaga : Scanning electron microscopy of the glomerular filtration membrane in the rat kidney. Cell Tiss. Res. 166: 299-314 (1976).

Fujita, T. J. Tokunaga and M. Miyoshi : Scanning electron microscopy of the podocytes of renal glomerulus. Arch. histol. jap. 32: 99-113 (1970).

Kobayashi, S.: Occurrence of unique colloidal particles in snake blood and their transport across the capillary wall. A proposal of a new hypothesis on the permeability of the blood capillaries. Arch. histol. jap. 31: 511-528 (1970a).

- Ferritin labeling in the fixed muscle capillary. A doubt on the tracer-experiments as the basis for the vesicular transport theory. Arch. histol. jap. 32: 81-86 (1970b).

Murakami, T.: A revised tannin-osmium method for non-coated scanning electron mircoscope specimens. Arch. histol. jap. 36: 189-193 (1974).

Palade, G. E. : The fine structure of blood capillaries. J. appl. Phys. 24: 1424 (1953). : Transport in quanta across the endothelium of blood capillaries. Anat. Rec. 136: 254 (1960).

Tokunaga, J., M. Edanaga, T. Fujita and K. Adachi : Freeze cracking of scanning electron microscope specimens. A study of the kidney and spleen. Arch. histol. jap. 37: 165-182 (1974).

Wolff, J.: Elektronenmikroskopische Untersuchungen über die Vesikulation im Kapillarenendothel. Lokalisation, Variation und Fusion der Vesikel. Z. Zellforsch. 73: 143-164 (1966).

Wolff, J. and H. J. Merker : Ultrastruktur und Bildung von Poren im Endothel von porösen und geschlossenen Kapillaren. Z. Zellforsch. 73: 174-191 (1966).

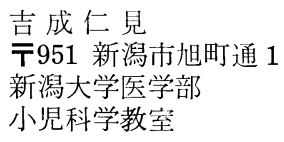

Dr. Toshimi Yoshinari

Department of Pediatrics

Niigata University School of Medicine

Niigata, 951 Japan 